\title{
XVIII Pharmaceutical Congress of Sao Paulo: Contributions to the improvement of Pharmacy in Brazil
}

The Pharmaceutical Congress of Sao Paulo is considered the biggest professional and scientific meeting in Latin America and in this year it was held together with the X International Seminar of Pharmaceutical Sciences and Expofar 2015. The Meeting is organized each two years by the Board of Directors of the Sao Paulo State Regional Council of Pharmacy (CRF-SP), who has been working on the valorization and progress of the pharmaceutical scope.

This edition of the event took place 10-13 October in Sao Paulo city and gathered about 30000 participants among pharmacists, researchers and students from all regions of Brazil. It was an opportunity for learning and exchange of experiences for students and professionals from different fields of activity of pharmacy.

The theme "Pharmaceutical Talents: today building the health of tomorrow" was incorporated in the scientific program, which was developed by a Committee formed by renowned professors and professionals in the pharmaceutical field.

The Scientific Program was organized in five areas: Pharmaceutical Assistance and Public Health, Industry and Technology, Clinical Analysis and Toxicology, Management and Regulatory Affairs, and Pharmaceutical Education. Novel and relevant topics were presented by more than 200 national and international speakers in 68 sessions including 29 lectures, 15 symposia, 11 round tables and 13 courses.

The opening lecture on "The clinical duties of the pharmacist and pharmaceutical prescription in Brazil," given by Dr. Tarcisio Palhano from the Universidade do Rio Grande do Norte, attracted over 400 participants on the first day of the event.

The closing lecture "The FIP strategy for valorization of the pharmaceutical career" was delivered by Professor Carmen Peña, the current President of the International Pharmaceutical Federation (FIP), who presented the perspectives and actions of the FIP for the appreciations of the pharmacist in the different areas of activity and primarily as healthcare professional.

During the Meeting, scientific works from 248 research groups from all regions of Brazil were presented at the poster and oral presentations sessions. Abstracts of these scientific contributions were published 


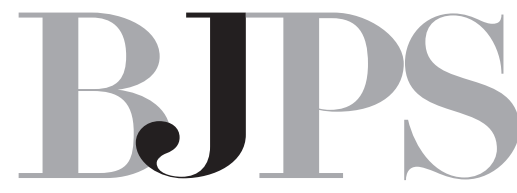

in the Brazilian Journal of Pharmaceutical Sciences. 52 (Suppl 2), 2015. The three best scientific works and three honorable mentions were awarded in each session.

The Expofar 2015 brought together 50 exhibitors, most of them within the pharmaceutical area, who released novel technologies, equipments and materials contributing to the development and expansion of pharmacy business and created opportunities for professional development.

The Board of Directors of the CRF-SP also organized extra activities during the Meeting called "The Pharmaceutical Scope" with seminars and workshops about Clinical Practices, Integrative and Complementary Practices, Technologies in Health, and Education and Public Health.

The Meeting also included other parallel activities organized by the Brazilian Association for Pharmaceutical Education, Brazilian Society of Community Pharmacy, Brazilian Society of Hospital Pharmacy, National Academy of Pharmacy, National Meeting of Homeopathic Pharmacists, National Association of Pharmaceutical Compounding, Association for Juvenile Diabetes and the International Symposium for Better Medicines for Children.

The activities of the scientific program and the organization of the event were highly praised by participants and speakers who were motivated and excited to participate again in 2017. I hope to meet you there.

Profa. Dra. Rosario Dominguez Crespo Hirata

FCF/USP 